
\title{
25 Research Soure \\ The Effect of Workplace Violence on Depression among Medical Staffs in China: The Mediating Role of Interpersonal Trust
}

Haipeng Wang

Shandong University

Yuxia Zhang

Shandong University Qilu Hospital

Long Sun ( $\square$ sunlong@sdu.edu.cn )

Shandong University https://orcid.org/0000-0002-3070-8427

\section{Research}

Keywords: Workplace violence, Interpersonal trust, Depression, Medical staff, China

Posted Date: April 2nd, 2020

DOI: https://doi.org/10.21203/rs.3.rs-19254/v1

License: (1) This work is licensed under a Creative Commons Attribution 4.0 International License.

Read Full License

Version of Record: A version of this preprint was published at International Archives of Occupational and Environmental Health on November 16th, 2020. See the published version at https://doi.org/10.1007/s00420-020-01607-5. 


\section{Abstract}

Background: Workplace violence has been recognized globally as a serious occupational hazard in health services occupations, and existing studies have identified that workplace violence can significantly lead to depression. Interpersonal trust, an important topic, also has been proved associated with workplace violence and depression. However, the moderating effect of interpersonal trust has not been tested before, which can help us to further understand the effect mechanism of workplace violence on depression.

Method: In the current study, we collected 3,426 valid questionnaires based on a cross-sectional design among medical staff in Chinese hospitals. Depression, workplace violence, interpersonal trust, social support, physical diseases, and some other social-demographic variables were evaluated.

Results: The data analyzed in the current study supported that there were $52.2 \%$ of medical staff experienced workplace violence before. Experiencing verbal violence $(b=2.99, p<0.001)$, experiencing physical violence $(b=3.70, p<0.01)$, experiencing both kinds of the violence $(b=4.84, p<0.001)$, high level of interpersonal trust $(b=0.22, p<0.001)$, nursing $(b=1.10, p<0.05)$, manager $(b=-1.72, p<0.001)$, suffering physical disease $(b=3.35, p<0.001)$, social support $(b=-0.23, p<0.001)$ were significantly associated with depression. Interpersonal trust had a partial mediating effect on the relationship between workplace violence and depression.

Conclusion: Interpersonal trust can be a mediator between workplace violence and depression. Some potential strategies would be beneficial to promoting the mental health status among medical staff.

\section{Background}

Workplace violence, which defined as incidents where staff is abused, threatened or assaulted in circumstances related to their work [1], has become one of the most important health issues worldwide [2, 3]. It can occur in many industries and professions, but people in some specific professions are believed to be at a higher risk of encountering workplace violence [4, 5]. Hospitals have been identified as one of the most violent workplace sectors, drawing the professional and public attention for this issue [6]. Previous studies also identified that medical staffs in hospitals were subject to a high risk of workplace violence due to close contact with patients and their relatives under stressful circumstances, and workplace violence has been recognized globally as a serious occupational hazard in health services occupations $[3,4,7]$. A study in hospitals participating in the Occupational Health Safety Network in United States reported that the overall rate of workplace violence injury increased by $23 \%$ annually during 2012-2015 [8].

In China, the incidence rate and the number of workplace violence towards doctors also have been increasing significantly over the past decade $[5,9]$. Some studies demonstrated that exposure to violence in healthcare settings may result in tension in doctor-patient relationships, decreased job satisfaction, reduced work performance, poor quality of care and patient care outcomes [10-14]. Moreover, it also can 
lead to a variety of adverse physical and mental health issues, such as occupational strain, depression, sleep disruption, injury, and poor quality of life among medical staff $[4,7]$.

As we introduced before, existing studies conducted in different countries have identified that workplace violence can significantly lead to depression $[3,6,7]$. Workplace violence, especially in the form of a direct threat to life, can result in the development of the post-traumatic disorder, stress, anxiety, and depression [15]. It was suggested that low self-esteem, poor morale and depression can result from exposure to verbal or physical violence at work in hospitals [6]. Several studies have documented the effects of workplace violence on health outcomes, such as depersonalization, depression, sleeplessness, poorer mental health, and traumatic stress disorder $[3,16]$. Previous studies have described increasing pessimism, anxiety and depression as psychological reactions occurring after exposure to violence [17]. In addition, it has been shown that health effects of workplace violence can last for years after the incidents due to fear or perceived threat [3].

In recent years, interpersonal trust had widely been paid more concern as an important research issue in economic and psychological trust literature. The concept of trust had been predominantly associated with situations of uncertainty and risk, and expectations about future behavior and interaction [18]. There were some studies found the relationship between interpersonal trust and mental disorders, such as depression [19]. It was demonstrated that lower levels of interpersonal trust were significantly associated with greater depression [20]. Prospective studies also had shown that a low level of interpersonal trust was independent risk factor for new-onset or long-term depression [21, 22]. Although there are few studies conducted among health workers, we have enough reasons to believe the association between interpersonal trust and depression.

When we reviewed the association between workplace violence and interpersonal trust, previous studies demonstrated that workplace violence can lead to a deteriorating trust-based doctor-patient relationship [23]. Interpersonal trust, a part of interpersonal relationships, should also associate with workplace violence. Besides, interpersonal conflict was an important factor associated with hospital workers which had been identified in previous studies [24]. As the association between and interpersonal conflict [25], we can also believe the effect of workplace violence on interpersonal trust. Until now, as we discussed before, there might be an interrelationship with interpersonal trust as a mediator between workplace violence and depression.

Among the literature on workplace violence, interpersonal trust and depression among medical staffs, most studies focus on their prevalence and related factors or effects on the workers [2, 3, 9, 14], while some studies have established their correlation with one another $[7,12,15,22,26]$. Whereas little information is known about the correlation between workplace violence, interpersonal trust and depression in healthcare settings. To fill knowledge gaps in previous findings, we conducted this study to explore the associations among workplace violence, interpersonal trust and depression after adjusting for covariates, and to identify the mediating role of interpersonal trust in the relationship between workplace violence and depression, using a dataset of medical staffs from Shandong province in China. If the 
relationship can be built, it is very helpful for us to develop interventions and strategies to reduce the negative psychological outcomes associated with experiencing workplace violence.

\section{Methods}

\subsection{Setting and participants}

In the current study, we collected 3,426 valid questionnaires based on a cross-sectional design in Shandong province, China. Shandong is a big province ranked second in the population [27], and the number of health workers also ranks first in China [28]. To get a more accurate description for the medical staff, a multiple stratified random cluster sampling method was used to select the medical staff. Firstly, we randomly selected one city based on the level of GDP per capita in 2017, and three cities (Qingdao, Dezhou, Zaozhuang) were selected in the current study. Secondly, three counties or districts were randomly selected from each city. Thirdly, one city-level and one county-level hospital were randomly selected from each city. Until now, we have selected 12 hospitals in the three cities (3 city-level hospitals and 9 county-level hospitals). Next, in city-level hospital, three inpatient areas from each department were randomly selected in each hospital. For the county-level hospital, two inpatient areas from each department were randomly selected in each hospital. All of the medical staff working on the interview date were employed in the interview.

\subsection{Data collection}

The data was collected from November 2018 to January 2019. For the interviewed medical staff, the questionnaire was sent to them individually, and they can fill it anonymously when they are free for the work. Two trained postgraduate students were in the hospital to answer the questions and collect the questionnaires on the interview date.

\subsection{Measures}

\subsubsection{Depression}

The Chinese version of the Center for Epidemiologic Studies-Depression Scale (CES-D) was used to assess the level of depression symptoms in the current study [29].It is a very popular scale with nice reliability and validity to evaluate depression [30,31]. The Chinese version of CES-D was also tested in previous studies [32]. There were 20 items in this scale, and the responses were the subjects' feelings for the number of days in the past week. The answers were 0 ( $<1$ day), 1 (1-2 days), 2 (3-4 days) and 3 (57 days). Cronbach's alpha was 0.852 in the current study.

\subsubsection{Workplace violence}

Workplace violence was evaluated by the question that "have you ever experienced the following behavior conducted by your patients and their relations?" the answer could choose from verbal violence (1), physical violence (2), both (3), and none (0). 


\subsubsection{Interpersonal trust}

We used the Interpersonal Trust Scale (ITS) to estimate the level of interpersonal trust [33]. The Chinese version of ITS had been identified with sound reliability and validity[34], which also had been used in several psychological studies [35]. It contains 25 items to measure interpersonal trust, and the answer can be chose from 1 (completely agree) to 5 (completely disagree). In the current study, the Cronbach's alpha was 0.859 .

\subsubsection{Social support}

We used the Multidimensional Scale of Perceived Social Support (MSPSS) to measure the level of social support in the current study[36, 37].Previous studies have tested the Chinese 12-item version of this scale with nice validity and reliability among Chinese adolescents[38]. The answer can choose from 1 (strongly disagree) to 7 (strongly agree). The total score (ranged from 12 to 84 ) was analyzed in the present study. The internal consistency was at a high level in the current study $(a=0.958)$.

\subsubsection{Physical disease}

Physical disease was evaluated by a question asking if the medical staff diagnosed with any physical disease. The answer was yes (1) and no (0).

\subsubsection{Social-demographic variables}

Gender was measured by male ( 1 ) and female ( 0 ). Age was assessed by the date of birth for the participants, and we calculated their age until the date we interviewed. Married status was estimated by single, married, divorced, widowed and others. As there were few subjects divorced or widowed, we categorized into single, married and others. Education was evaluated by the academic degree they received. The answers were doctor, master, bachelor, and others.

\subsubsection{Work-related variables}

As we interviewed three kinds of medical staff in the current study, the types of medical staff were doctor, nursing and medical technician. The professional title was measured by senior, vice-senior, intermediate, and junior and others. The manager was evaluated by yes (1) or no (0) with the former contained director of the hospital, vice-director of the hospital, director of the department, vice-director of the department, head nurse and deputy nurse.

\subsection{Statistical analysis}

IBM SPSS Statistics 24.0 (Web Edition) was used to analyze the data in the current study. T-tests, oneway ANOVA, or bivariate analysis was performed to analyze the factors associated with depression among medical staff. Linear regression was conducted to examine the factors associated with depression, and dummy variables were set for the variables with multi-classification. SPSS macros program (PROCESS v3.3) developed by Andrew F. Hayes was used to conduct to test the mediating effect 
of interpersonal trust [39]. All of the tests were two-tailed and a p-value of $\leq 0.05$ was considered statistically significant.

\section{Results}

In the current study, we totally interviewed 3,426 medical staff in Shandong province, China. Description of the sample was listed in the second column in Table 1 . We found that there were $52.2 \%$ of medical staff experienced workplace violence. In this table, we also analyzed the factors associated with depression. The results supported the depression was associated with gender $(t=10.98, p<0.001)$, professional title $(F=2.74, p<0.05)$, manager $(t=-4.76, p<0.001)$, physical disease $(t=7.96, p<0.001)$, social support $(r=-0.37, p<0.001)$, interpersonal trust $(r=0.30, p<0.001)$, and workplace violence $(F=$ $65.68, p<0.001)$. 
Table 1

Characteristics and the single analysis of depression

\begin{tabular}{|c|c|c|c|c|}
\hline & Mean \pm SD/n(\%) & Depres & & \\
\hline & & Mean & SD & $t / F / r$ \\
\hline All & $3426(100.0)$ & 14.72 & 10.38 & - \\
\hline Gender & & & & $10.98^{\star \star \star}$ \\
\hline Male & $919(26.8)$ & 16.35 & 10.83 & \\
\hline Female & $2507(73.2)$ & 12.29 & 9.17 & \\
\hline Age & $35.14 \pm 8.42$ & 14.72 & 10.38 & $-0.04^{\star}$ \\
\hline Married Status & & & & 2.72 \\
\hline Single & $577(16.8)$ & 15.63 & 10.41 & \\
\hline Married & $2802(81.8)$ & 14.53 & 10.34 & \\
\hline Others & $47(1.4)$ & 14.28 & 11.88 & \\
\hline Education & & & & 0.62 \\
\hline Doctor & $56(1.6)$ & 15.48 & 10.56 & \\
\hline Master & $562(16.4)$ & 15.18 & 10.80 & \\
\hline Bachelor & $2368(69.1)$ & 14.64 & 10.35 & \\
\hline Others & $440(12.8)$ & 14.45 & 10.01 & \\
\hline Types of medical staff & & & & 0.64 \\
\hline Doctor & $1268(37.0)$ & 14.77 & 10.62 & \\
\hline Nursing & $1695(49.5)$ & 14.81 & 10.04 & \\
\hline Medical technician & $463(13.5)$ & 14.21 & 10.96 & \\
\hline Professional title & & & & $2.74^{\star}$ \\
\hline Senior & 109 (3.2) & 13.82 & 10.69 & \\
\hline Vice-senior & $303(8.8)$ & 13.40 & 10.64 & \\
\hline Intermediate & $1170(34.2)$ & 14.57 & 10.60 & \\
\hline Junior and others & $1844(53.8)$ & 15.08 & 10.16 & \\
\hline Manager & & & & $-4.76^{\star \star \star}$ \\
\hline
\end{tabular}

Note: SD refers to standard deviation. ${ }^{*}$ means $p<0.05 . * \star$ means $p<0.01 . * \star \star$ means $p<0.001$. 


\begin{tabular}{|c|c|c|c|c|}
\hline & \multirow[t]{2}{*}{ Mean \pm SD/n(\%) } & \multicolumn{3}{|c|}{ Depression } \\
\hline & & Mean & SD & $t / F / r$ \\
\hline Yes & $659(19.2)$ & 12.99 & 10.27 & \\
\hline No & $2767(80.8)$ & 15.13 & 10.37 & \\
\hline Physical disease & & & & $7.96 * \star \star$ \\
\hline Yes & $457(13.3)$ & 18.28 & 11.80 & \\
\hline No & 2969 (86.7) & 14.17 & 10.03 & \\
\hline Social support & $62.46 \pm 13.82$ & 14.72 & 10.38 & 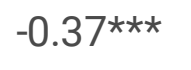 \\
\hline Interpersonal trust & $76.02 \pm 8.80$ & 14.72 & 10.38 & $0.30 * \star \star$ \\
\hline Workplace Violence & & & & $65.68^{\star \star *}$ \\
\hline None & $1638(47.8)$ & 12.29 & 8.17 & \\
\hline Verbal violence & 1299 (37.9) & 16.35 & 10.83 & \\
\hline Physical violence & $44(1.3)$ & 18.15 & 8.32 & \\
\hline Both & $445(13.0)$ & 18.53 & 11.22 & \\
\hline
\end{tabular}

Linear regression was used to analyze the factors associated with depression in Table 2. Firstly, we analyzed the association without interpersonal trust in Model A. The results supported that workplace violence associated with depression. In Model $B$, when adding interpersonal trust into the regression, both workplace violence and interpersonal trust $(\beta=0.22, p<0.001)$ were also associated with depression. However, all of the partial regression coefficients of workplace violence had decreased. It implied us the mediating effect of interpersonal trust on the association between workplace violence and depression. The other associated factors were nursing $(\beta=1.10, p<0.05)$, manager $(\beta=-1.72, p<0.001)$, physical disease $(\beta=3.35, p<0.001)$, social support $(\beta=-0.23, p<0.001)$. 
Table 2

Linear regression analysis for depression among medical staffs [ $\beta(95 \% \mathrm{Cl})]$

\begin{tabular}{|c|c|c|}
\hline & Model A & Model B \\
\hline Male & $0.69(-0.15,1.52)$ & $0.55(-0.27,1.36)$ \\
\hline Age & $-0.04(-0.10,0.02)$ & $-0.02(-0.08,0.04)$ \\
\hline \multicolumn{3}{|l|}{$\begin{array}{l}\text { Married status } \\
\text { (Ref.=others) }\end{array}$} \\
\hline Single & $-0.33(-3.16,2.50)$ & $-0.02(-2.79,2.76)$ \\
\hline Married & $-0.66(-3.36,2.04)$ & $-0.66(-3.30,1.99)$ \\
\hline \multicolumn{3}{|l|}{$\begin{array}{l}\text { Education } \\
\text { (Ref.=others) }\end{array}$} \\
\hline Doctor & $-0.38(-3.10,2.33)$ & $-0.54(-3.20,2.12)$ \\
\hline Master & $0.57(-0.74,1.87)$ & $0.23(-1.05,1.50)$ \\
\hline Bachelor & $-0.06(-1.03,0.91)$ & $-0.30(-1.25,0.66)$ \\
\hline \multicolumn{3}{|c|}{$\begin{array}{l}\text { Types of medical staff } \\
\text { (Ref.= Medical technician) }\end{array}$} \\
\hline Doctor & $-0.35(-1.38,0.69)$ & $-0.09(-1.11,0.93)$ \\
\hline Nursing & $0.92(-0.10,1.94)$ & $1.10(0.10,2.10) *$ \\
\hline \multicolumn{3}{|c|}{$\begin{array}{l}\text { Professional title } \\
\text { (Ref.= Junior and others) }\end{array}$} \\
\hline Senior & $-0.58(-2.89,1.73)$ & $-0.35(-2.62,1.92)$ \\
\hline Vice-senior & $-1.07(-2.67,0.53)$ & $-0.89(-2.46,0.68)$ \\
\hline Intermediate & $-0.42(-1.31,0.46)$ & $-0.28(-1.15,0.58)$ \\
\hline Manager & $-1.84(-2.83,-0.85)^{\star \star \star}$ & $-1.72(-2.69,-0.75)^{\star \star \star}$ \\
\hline Physical disease & 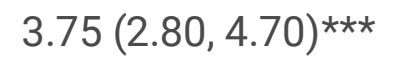 & 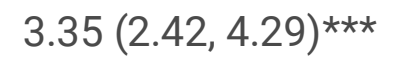 \\
\hline Social support & $-0.26(-0.28,-0.24)^{\star \star \star}$ & $-0.23(-0.25,-0.20)^{\star \star \star}$ \\
\hline Interpersonal trust & -- & $0.22(0.18,0.26)^{\star \star \star}$ \\
\hline \multicolumn{3}{|l|}{$\begin{array}{l}\text { Workplace Violence } \\
\text { (Ref.= None) }\end{array}$} \\
\hline Verbal violence & $3.55(2.86,4.23)^{\star \star \star}$ & $2.99(2.32,3.67)^{\star \star \star}$ \\
\hline Physical violence & $4.09(1.28,6.90)^{\star \star}$ & $3.70(0.94,6.45)^{\star \star}$ \\
\hline
\end{tabular}

Note: Ref. means reference. ${ }^{*}$ means $p<0.05 .{ }^{* *}$ means $p<0.01 .{ }^{*} * *$ means $p<0.001$. 


\begin{tabular}{|lll|}
\hline & Model A & Model B \\
\hline Both & $5.55(4.55,6.56)^{\star \star \star}$ & $4.84(3.85,5.83)^{\star \star \star}$ \\
\hline Constant & $17.01(11.83,22.20)^{\star \star \star}$ & $11.34(6.38,16.31)^{\star \star \star \star}$ \\
\hline $\mathrm{R}^{2}$ & 0.20 & 0.23 \\
\hline Note: Ref. means reference. * means $\mathrm{p}<0.05 .{ }^{* \star}$ means $\mathrm{p}<0.01 .{ }^{\star \star \star}$ means $\mathrm{p}<0.001$. \\
\hline
\end{tabular}

As the implication of the linear regression, we analyzed the mediating effect of interpersonal trust on the association between workplace violence and depression. The results were shown in Table 3, and we found that interpersonal trust can be a mediator between workplace violence and depression. The findings supported a partial effect. The indirect effects can explain about $20 \%\left(1.36^{\star} 0.32 / 2.27\right)$ of the total effect.

Table 3

Mediating effect of interpersonal trust between workplace violence and depression among medical staffs

\begin{tabular}{|llllll|}
\hline Path & Independent variable & Dependent variable & $\boldsymbol{\beta}$ & SE & $\mathbf{P}$ \\
\hline a & Workplace violence & Interpersonal trust & 1.36 & 0.15 & $<0.001$ \\
\hline b & Interpersonal trust & Depression & 0.32 & 0.02 & $<0.001$ \\
\hline c & $\begin{array}{l}\text { Workplace violence } \\
\text { (without interpersonal trust) }\end{array}$ & Depression & 2.27 & 0.18 & $<0.001$ \\
\hline c' & $\begin{array}{l}\text { Workplace violence } \\
\text { (with interpersonal trust) }\end{array}$ & Depression & 1.83 & 0.17 & $<0.001$ \\
\hline Note: $\beta$ is the partial regression coefficient, and SE is its standard error. & \\
\hline
\end{tabular}

\section{Discussion}

\subsection{The main findings}

This study presents critical information on the current profile of workplace violence, interpersonal trust, depression and their relationships among medical staff in Chinese hospitals. More than half of the medical staff were found to be experiencing workplace violence and suffering from depression, especially those who were male, nurses, and non-managers. Workplace violence had a significant direct effect on interpersonal trust and depression, while interpersonal trust had a significant direct effect on depression. Moreover, there was a significant indirect effect of workplace violence on depression through interpersonal trust as a mediator. In addition, social support was a protective factor of depression, whereas physical diseases were significantly associated with a higher risk of depression. We should pay 
more attention to these findings, because workplace violence and depression could not only lead to the health issues of medical staffs, but also negatively affect their work performance and the efficiency of health system in the long term.

\subsection{The prevalence of workplace violence and depression}

The prevalence of workplace violence experienced by hospital medical staff in this study was $52.2 \%$, which was lower than some of previous studies in China [12,40]. The prevalence of workplace violence in hospitals varies in different studies, and it is difficult to draw comparisons between studies [10]. This may be due to cultural differences in the perception of workplace violence in different countries, or because of the diversity of definitions, assessment scales, study designs and settings used in different studies [13, 40]. Numerous studies have found high levels of workplace violence among hospital health workers, and it has become more frequent and severe in recent years [2]. This study also showed that hospital medical staff were suffering from depressive symptoms. These results indicated that the risks of Chinese medical staff being experiencing workplace violence and depression are very high, which may be due to the increasing contradiction and decreasing trust between physicians and patients in China. It has been shown that poor doctor-patient relationships may increase the risk of depressive symptoms among Chinese doctors [41]. The majority of the victims of workplace violence became vigilant in the clinical environment and worried about personal safety while seeing patients [42]. Therefore, targeting strategies are essential to tackle the workplace violence and depression of medical staff from the health system perspective.

\subsection{The impact of workplace violence on depression}

The study also found that medical staffs who have experienced workplace violence were more likely to suffer from depression than the others, which is consistent with the results of previous studies $[3,5,6$, 15]. In addition, medical staff who have encountered both physical violence and verbal violence at workplace may suffer from highest level of depression, followed by these experiencing physical violence and these exposed to verbal violence. When encountering workplace violence, the health workers may think they do not receive respect and recognition from their patients, so they begin to doubt their professional value and status [40]. Eventually, it can lead to a marked decline in enthusiasm and empathy, and a significant increase in anxiety and depression [5]. Therefore, building a harmonious medical environment and reducing the prevalence of workplace violence is one effective measure to alleviate or avoid the depressive symptoms of medical staff. Additionally, the findings demonstrated that some personal and professional features were significantly associated with depression among the medical staffs. Thus, targeted strategies should be taken for the special groups, such as the male, nurses, and non-managers. Furthermore, social support plays an important role in alleviating the depression for the health workers.

\subsection{The mediating effect of interpersonal trust on workplace violence and depression}


Our findings also demonstrated that interpersonal trust played a mediating role in the impact of workplace violence on the medical staffs' depression. The results showed that the indirect effect was positive and can be considered as a supplementary mediation, indicating that a partial effect of the mediating role of interpersonal trust was established. Obviously, these findings corresponded to the results of single analysis and linear regression analysis. Similarly, previous studies showed that social support played a role in mitigating or mediating the impact of workplace violence on job burnout and turnover intention of physicians $[40,43,44]$. It is noteworthy that workplace violence was negatively correlated with interpersonal trust. Perceived interpersonal trust can play an important role in alleviating the potential stress and anxiety induced by workplace violence, which will, in turn, mediate depressive symptoms. It has been indicated that peer support plays an important role in preventing the development of depression among employees experiencing workplace violence [6]. When medical staffs suffer violence in the workplace, the importance of interpersonal trust is highlighted, and positive measures (such as encouragement and support from their colleagues and managers) should be taken in a timely manner to help them reduce the consequence caused by workplace violence [5, 40]. Moreover, hospitals should strengthen the training and management of health professionals to reduce the harm to them from workplace violence $[6,40]$.

\subsection{Limitations}

Although there were some significant findings in this study, several limitations should be noted. First, the measurement of workplace violence was obtained by using a self-reporting question, so the recall bias might have an impact on the results. Second, it was a cross-sectional study revealing the status of the research variables at a certain time, thus the interpretation of the causal relationship between the variables was limited. It will be of benefit to confirm the causality with longitudinal data in future studies. Third, the sample was selected from three cities of one province, which might compromise the representativeness of the sample, so the extrapolation of conclusions at the national level could be challenged. But we achieved a large sample size of 3,426 health workers across city-level and countylevel hospitals in various cities and counties. Our findings still provided new insights for the managers to maintain the stability of medical staff.

\section{Conclusions}

In conclusion, there is a high prevalence of workplace violence against medical staff in city-level and county-level hospitals. Health workers encountering workplace violence were more likely to suffer from depression than the others. Workplace violence had not only direct effects on interpersonal trust and depression, but also an indirect effect on depression through interpersonal trust as a mediator. More attention to workplace violence and depression in hospitals should be warranted. The findings suggested practical implications and policy-making references for hospital management. Preventive and managing measures, such as establishing organizational mechanisms and reporting system, and providing training programs for health professionals, are urgently needed to deal with workplace violence and depression in hospitals. Such potential strategies would be beneficial in promoting the stability of medical staff. 


\section{Abbreviations}

NHC: National Health Commission of China; GDP: Gross National Product; CES-D: Center for Epidemiologic Studies-Depression Scale; ITS: Interpersonal Trust Scale; MSPSS: Multidimensional Scale of Perceived Social Support; ANOVA: Analysis of Variance.

\section{Declarations}

\section{Ethics approval and consent to participate}

The institutional review board of Shandong University School of Public Health (ref.:20181219) approved the study protocol before data collection. Informed consent was obtained from all of the participants.

\section{Consent for publication}

Not applicable.

\section{Availability of data and materials}

The datasets used and/or analysed during the current study are available from the corresponding author on reasonable request.

\section{Compting interests}

The authors declare that they have no competing interests.

\section{Funding}

The research was supported by the National Natural Science Foundation of China (71603149 and 71974114), Shandong Provincial Natural Science Foundation (ZR2016HQ01) and Shandong University (IFYT18033).

\section{Authors' contributions}

All authors read and approved the final manuscript. HW wrote the manuscript, $\mathrm{YZ}$ collected the data and comment on the draft of this manuscript, LS designed the study and analyzed the data.

\section{Acknowledgements}

We would like to thank Yue Teng, Tingting Liu, Wei Sun for their assistance in data collection.

\section{References}

1. (ILO) ILO, (ICN) ICoN, (WHO) WHO, (PSI) PSI: Framework guidelines for addressing workplace violence in the health sector. Geneva; 2002. 
2. Li Z, Yan C, Shi L, Mu H, Li X, Li A, Zhao C, Sun T, Gao L, Fan LJPO: Workplace violence against medical staff of Chinese children's hospitals: A cross-sectional study. PLOS ONE 2017, 12:01793730179373.

3. Hanson G, Perrin NA, Moss H, Laharnar N, Glass NEJBPH: Workplace violence against homecare workers and its relationship with workers health outcomes: a cross-sectional study. BMC Public Health 2015, 15:11-11.

4. Johansen IH, Baste V, Rosta J, Aasland OG, Morken TJBO: Changes in prevalence of workplace violence against doctors in all medical specialties in Norway between 1993 and 2014: a repeated cross-sectional survey. BMJ Open 2017, 7.

5. Zhao S, Xie F, Wang J, Shi Y, Zhang S, Han X, Sun Z, Shi L, Li Z, Mu HJAoPN: Prevalence of Workplace Violence Against Chinese Nurses and Its Association with Mental Health: A Crosssectional Survey. Archives of Psychiatric Nursing 2017, 32:242-247.

6. Hsieh $\mathrm{H}$, Chen Y, Wang H, Chang S, Ma SJJoCN: Association among components of resilience and workplace violence-related depression among emergency department nurses in Taiwan: a crosssectional study. Journal of Clinical Nursing 2016, 25:2639-2647.

7. Wu S, Lin S, Li H, Chai W, Zhang Q, Wu Y, Zhu WJAoE, Health O: A study on workplace violence and its effect on quality of life among medical professionals in China. Archives of Environmental \& Occupational Health 2014, 69:81-88.

8. Groenewold MR, Sarmiento RFR, Vanoli K, Raudabaugh W, Nowlin S, Gomaa A: Workplace violence injury in 106 US hospitals participating in the Occupational Health Safety Network (OHSN), 20122015. Am J Ind Med 2018, 61:157-166.

9. Shi J, Wang S, Zhou P, Shi L, Zhang Y, Bai F, Xue D, Zhang XJPO: The Frequency of Patient-Initiated Violence and Its Psychological Impact on Physicians in China: A Cross-Sectional Study. PLOS ONE 2015, 10.

10. Jiao M, Ning N, Li Y, Gao L, Cui Y, Sun H, Kang Z, Liang L, Wu Q, Hao YJBO: Workplace violence against nurses in Chinese hospitals: a cross-sectional survey. BMJ Open 2015, 5.

11. Zhang L, Wang A, Xie X, Zhou Y, Li J, Yang L, Zhang JJIJoNS: Workplace violence against nurses: A cross-sectional study. International Journal of Nursing Studies 2017, 72:8-14.

12. Sun T, Gao L, Li F, Shi Y, Xie F, Wang J, Wang S, Zhang S, Liu W, Duan XJBO: Workplace violence, psychological stress, sleep quality and subjective health in Chinese doctors: a large cross-sectional study. BMJ Open 2017, 7.

13. Magnavita N, Heponiemi TJBHSR: Violence towards health care workers in a Public Health Care Facility in Italy: a repeated cross-sectional study. BMC Health Services Research 2012, 12:108-108.

14. Chen S, Lin S, Ruan Q, Li H, Wu SJAoE, Health O: Workplace violence and its effect on burnout and turnover attempt among Chinese medical staff. Archives of Environmental \& Occupational Health 2016, 71:330-337.

15. Zafar W, Khan UR, Siddiqui SA, Jamali S, Razzak JA: Workplace Violence and Self-reported Psychological Health: Coping with Post-traumatic Stress, Mental Distress, and Burnout among 
Physicians Working in the Emergency Departments Compared to Other Specialties in Pakistan. The Journal of Emergency Medicine 2016, 50:167-177.e161.

16. da Silva AT, Peres MF, Lopes Cde S, Schraiber LB, Susser E, Menezes PR: Violence at work and depressive symptoms in primary health care teams: a cross-sectional study in Brazil. Soc Psychiatry Psychiatr Epidemiol 2015, 50:1347-1355.

17. Inoue M, Tsukano K, Muraoka M, Kaneko F, Okamura HJP, Neurosciences C: Psychological impact of verbal abuse and violence by patients on nurses working in psychiatric departments. Psychiatry and Clinical Neurosciences 2006, 60:29-36.

18. Brennan N, Barnes RK, Calnan MW, Corrigan O, Dieppe PA, Entwistle VJIJfQiHC: Trust in the healthcare provider-patient relationship: a systematic mapping review of the evidence base. International Journal for Quality in Health Care 2013, 25:682-688.

19. Kim JY, Yoon J, Kim MH, Kim SJPM: Association between interpersonal trust, reciprocity, and suicidal behaviors: A longitudinal cohort study in South Korea. Preventive Medicine 2017, 99:218-221.

20. Bova CA, Route PS, Fennie KP, Ettinger WH, Manchester GW, Weinstein BJRiN, Health: Measuring patient-provider trust in a primary care population: Refinement of the health care relationship trust scale. Research in Nursing \& Health 2012, 35:397-408.

21. Kouvonen A, Oksanen T, Vahtera J, Stafford M, Wilkinson RG, Schneider J, Vaananen A, Virtanen M, Cox SJ, Pentti JJAJoE: Low workplace social capital as a predictor of depression - The Finnish public sector study. Am J Epidemiol 2008, 167:1143-1151.

22. Kim S, Chung Y, Perry MJ, Kawachi I, Subramanian SVJPO: Association Between Interpersonal Trust, Reciprocity, and Depression in South Korea: A Prospective Analysis. PLOS ONE 2012, 7.

23. Kornhaber R, Walsh K, Duff J, Walker KJJomh: Enhancing adult therapeutic interpersonal relationships in the acute health care setting: an integrative review. Journal of multidisciplinary healthcare 2016, 9:537-546.

24. Arnetz J, Hamblin LE, Sudan S, Arnetz B: Organizational Determinants of Workplace Violence Against Hospital Workers. J Occup Environ Med 2018, 60:693-699.

25. Ruz M, Tudela P: Emotional conflict in interpersonal interactions. Neuroimage 2011, 54:1685-1691.

26. Fujiwara T, Kawachi IJJoE, Health C: A prospective study of individual-level social capital and major depression in the United States. J Epidemiol Community Health 2008, 62:627-633.

27. NBS: Chinese Statistics Yearbook. Beijing, China: China Statistics Press; 2019.

28. NHC: Chinese Health Statistics Yearbook 2019. Beijing, China: China union medical college press; 2019.

29. Radloff LS: The CES-D Scale: A self-report depression scale for research in the general population. Applied Psychological Measurement 1977, 1:385-401.

30. Lewinsohn PM, Seelely JR, Roberts EE, Allen NB: Center for Epidemiologic Studies Depression Scale (CES-D) as a screening instrument for depression among community-residing older adults. Psychology and Aging 1997, 12:277-287. 
31. Fountoulakis K, Lacovides A, Kleanthous S, Samolis S, Kaprinis SG, Sitzoglou K, St Kaprinis G, Bech P: Reliability, Validity and Psychometric Properties of the Greek Translation of the Center for Epidemiological Studies-Depression (CES-D) Scale. BMC Psychiatry 2001, 1:3.

32. Cheung YB, Law CK, Chan B, Liu KY, Yip PSF: Suicidal ideation and suicidal attempts in a populationbased study of Chinese people: risk attributable to hopelessness, depression, and social factors. Journal of Affective Disorders 2006, 90:193-199.

33. Wright TL, Tedeschi RG: Factor anlaysis of the Interpersonal Trust Scale. Journal of Consulting and Clinical Psychology 1975, 43:470-477.

34. Zhao Z, Xiuya L: A revise of Interpersonal Trust Scale of High School Students. Journal of Mudanjiang College of Education 2015, 165:128-130.

35. Ziqiang X: A Cross-temporal Meta-analysis of Changes in Chinese College Students' Interpersonal Trust Advances in Psychological Science 2012, 20:344-353.

36. Zimet GD, Powell SS, Farley GK, Werkman S, Berkoff KA: Psychometric characteristics of the Multidimensional Scale of Perceived Social Support. J Pers Assess 1990, 55:610-617.

37. Zimet GD, Dahlem NW, Zimet SG, Farley GK: The Multidimensional Scale of Perceived Social Support. Journal of Personality Assessment 1988, 52:30-41.

38. Chou KL: Assessing Chinese adolescents' social support: The Multidimensional Scale of Perceived Social Support. Personality and Individual Differences 2000, 28:299-307.

39. Hayes AF, Rockwood NJ: Conditional Process Analysis: Concepts, Computation, and Advances in the Modeling of the Contingencies of Mechanisms. American Behavioral Scientist 2019, epub.

40. Duan X, Ni X, Shi L, Zhang L, Ye Y, Mu H, Li Z, Liu X, Fan L, Wang YJH, Outcomes QoL: The impact of workplace violence on job satisfaction, job burnout, and turnover intention: the mediating role of social support. Health and Quality of Life Outcomes 2019, 17:93.

41. Wang J, Sun W, Chi T, Wu H, Wang LJIAoO, Health E: Prevalence and associated factors of depressive symptoms among Chinese doctors: a cross-sectional survey. International Archives of Occupational and Environmental Health 2010, 83:905-911.

42. Yang SZ, Wu D, Wang N, Hesketh T, Sun KS, Li L, Zhou XJBO: Workplace violence and its aftermath in China's health sector: implications from a cross-sectional survey across three tiers of the health system. BMJ Open 2019, 9.

43. Courcy F, Morin AJS, Madore I: The Effects of Exposure to Psychological Violence in the Workplace on Commitment and Turnover Intentions: The Moderating Role of Social Support and Role Stressors. $J$ Interpers Violence 2019, 34:4162-4190.

44. Couto MT, Lawoko SJJoOH: Burnout, Workplace Violence and Social Support among Drivers and Conductors in the Road Passenger Transport Sector in Maputo City, Mozambique. J Occup Health 2011, 53:214-221. 